WRI-01-R009

\title{
FUELS IN SOIL TEST KIT: FIELD USE OF DIESEL DOG ${ }^{\circledR}$ SOIL TEST KITS
}

Topical Report

By

John F. Schabron

Susan S. Sorini

Joseph F. Rovani, Jr.

May 2001

Work Performed Under Cooperative Agreement

DE-FC26-98FT40323 Task 9

For

U.S. Department of Energy

Office of Fossil Energy

National Energy Technology Laboratory

Morgantown, West Virginia

By

Western Research Institute

Laramie, Wyoming 


\section{ACKNOWLEDGMENTS}

Funding for this study was provided by the U.S. Department of Energy, National Energy Technology Laboratory, under Cooperative Agreement DE-FC26-98FT40323. The cosponsors include the Wyoming Department of Environmental Quality (DEQ), F.E. Warren Air Force Base, Gradient Corporation, The Johnson Company, IT Corporation, TRC Environmental Corporation, Stone Environmental, ENSR, Action Environmental, Laco Associates, Barenco, Brown and Caldwell, Dames and Moore Lebron LLP, Phillips Petroleum, GeoSyntek, and the State of New Mexico.

\section{DISCLAIMER}

This report was prepared as an account of work sponsored by an agency of the United States Government. Neither the United States Government nor any agency thereof, nor any of their employees, makes any warranty, expressed or implied, or assumes any legal liability or responsibility for the accuracy, completeness, or usefulness of any information, apparatus, product, or process disclosed, or represents that its use would not infringe on privately owned rights. Reference herein to any specific commercial product, process, or service by trade name, trademark, manufacturer, or otherwise does not necessarily constitute or imply its endorsement, recommendation, or favoring by the United States Government or any agency thereof. The views and opinions of authors expressed herein do not necessarily state or reflect those of the United States Government or any agency thereof. 


\begin{abstract}
Western Research Institute (WRI) is commercializing Diesel Dog ${ }^{\circledR}$ Portable Soil Test Kits for performing analysis of fuel-contaminated soils in the field. The technology consists of a method developed by WRI (U.S. Patents 5,561,065 and 5,976,883) and hardware developed by WRI that allows the method to be performed in the field (patent pending). The method is very simple and does not require the use of highly toxic reagents. The aromatic components in a soil extract are measured by absorption at $254 \mathrm{~nm}$ with a field-portable photometer. WRI added significant value to the technology by taking the method through the American Society for Testing and Materials (ASTM) approval and validation processes. The method is designated ASTM Method D-5831-96, Standard Test Method for Screening Fuels in Soils. This ASTM designation allows the method to be used for federal compliance activities. In FY 99, twenty-five preproduction kits were successfully constructed in cooperation with CF Electronics, Inc., of Laramie, Wyoming. The kit components work well and the kits are fully operational. In the calendar year 2000, kits were provided to the following entities who agreed to participate as FY 99 and FY 00 JSR (Jointly Sponsored Research) cosponsors and use the kits as opportunities arose for field site work: Wyoming Department of Environmental Quality (DEQ) (3 units), F.E. Warren Air Force Base, Gradient Corporation, The Johnson Company (2 units), IT Corporation (2 units), TRC Environmental Corporation, Stone Environmental, ENSR, Action Environmental, Laco Associates, Barenco, Brown and Caldwell, Dames and Moore Lebron LLP, Phillips Petroleum, GeoSyntek, and the State of New Mexico. By early 2001, ten kits had been returned to WRI following the six-month evaluation period. On return, the components of all ten kits were fully functional. The kits were upgraded with circuit modifications, new polyethylene foam inserts, and updated instruction manuals.
\end{abstract}

Some of the kits had been used for site evaluation and cleanup activities. ENSR, of Acton, Massachusetts, used a Diesel Dog Portable Soil Test Kit to evaluate sites in the Virgin Islands and Georgia. Barenco, Inc. is using a Diesel Dog Portable Soil Test Kit for site evaluation at a paper mill site in Canada. A small spill of about three gallons of diesel fuel was cleaned up in the Laramie, Wyoming, area in one morning using a Diesel Dog Soil Test Kit. The Wyoming DEQ successfully used a Diesel Dog Soil Test Kit for a cleanup project at a decades-old, fuel-contaminated site near Jackson, Wyoming. The site was contaminated with diesel fuel and road oil in a heavy, wet clay. Other sites were also excavated by the Wyoming DEQ.

A poster describing field use of the Diesel Dog Soil Test Kit was presented at the EPA/ACS Waste Testing and Quality Assurance Symposium in Washington, D.C. in August 2000. An invited presentation on method development activities leading to Diesel Dog Soil Test Kit development was made at the Dine' Navajo Nation College at Shiprock, New Mexico, in August 2000. A Diesel Dog Soil Test Kit was shown at contaminated soils and groundwater conferences in San Diego, California, in March 2000 and Amherst, Massachusetts, in October 2000. An abstract on Diesel Dog Soil Test Kit use was prepared with Eric Butler of Gradient Corp., Cambridge, Massachusetts, for the First 
International Congress on Petroleum Contaminated Soils, Sediments \& Water, which will be held in London in August 2001. 


\section{TABLE OF CONTENTS}

\section{Page}

LIST OF TABLES AND FIGURES $\ldots \ldots \ldots \ldots \ldots \ldots \ldots \ldots \ldots \ldots \ldots \ldots$

EXECUTIVE SUMMARY $\ldots \ldots \ldots \ldots \ldots \ldots \ldots \ldots \ldots \ldots \ldots \ldots \ldots$ vii

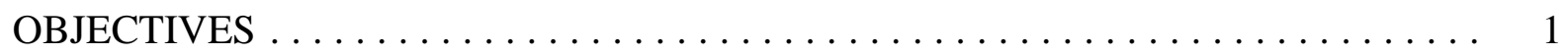

INTRODUCTION $\ldots \ldots \ldots \ldots \ldots \ldots \ldots \ldots \ldots \ldots \ldots \ldots \ldots \ldots \ldots \ldots \ldots$

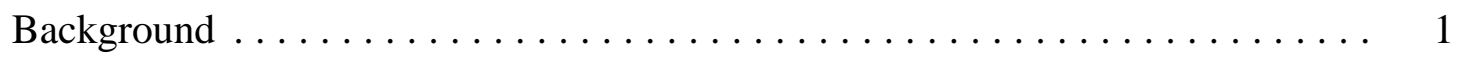

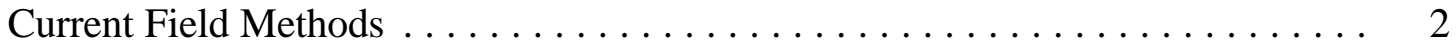

WRI Diesel Dog Portable Soil Test Kit Technology . . . . . . . . . . . . . 3

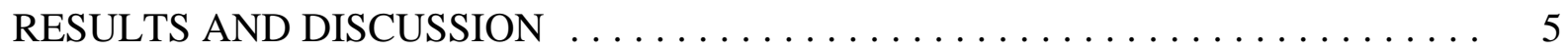

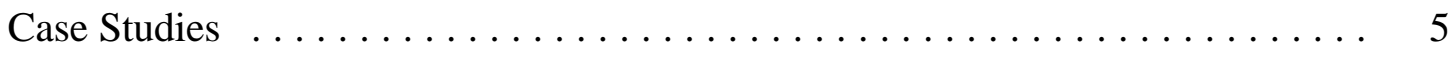

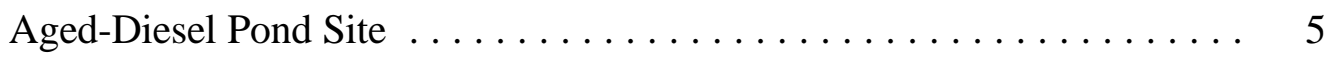

Diesel-Contaminated Site ..................... 5

Decades-Old Diesel and Road Tar Site ................. 6

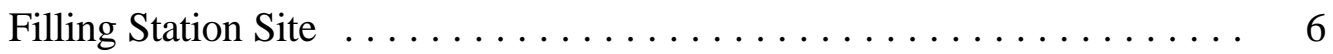

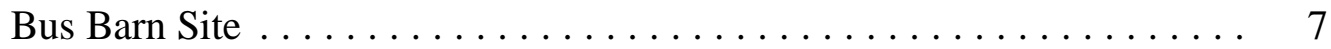

Emergency Response for Diesel Spill . . . . . . . . . . . . . 7

Underground Storage Tank Site $\ldots \ldots \ldots \ldots \ldots \ldots$

Communication of Results $\ldots \ldots \ldots \ldots \ldots \ldots \ldots \ldots \ldots \ldots \ldots$

CONCLUSIONS $\ldots \ldots \ldots \ldots \ldots \ldots \ldots \ldots \ldots \ldots \ldots \ldots \ldots \ldots \ldots \ldots \ldots$

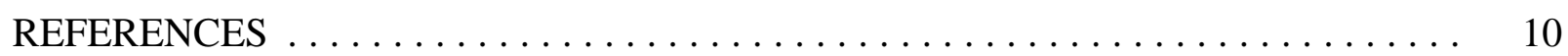




\section{LIST OF TABLES AND FIGURES}

$\underline{\text { Table }}$

$\underline{\text { Page }}$

1. Diesel Dog Test Kit (ASTM D-5831) Field Data and MADEP EPH

Lab Data for Domino Oil/Enighed Pond Site, $\mathrm{mg} / \mathrm{kg} \ldots \ldots \ldots \ldots \ldots$

2. Diesel Dog Test Kit (ASTM D-5831) Field Data and

EPA SW846 8015B Lab Data for Proprietary Diesel

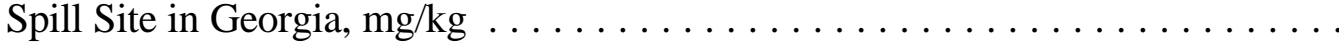

3. Diesel Dog Test Kit (ASTM D-5831) Field Data and EPA SW846 8015B

Lab Data for Decades-Old Diesel and Road Tar Site

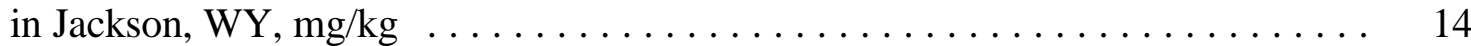

4. Diesel Dog Test Kit Analysis Results at Diesel Spill

Emergency Response Site . . . . . . . . . . . . . . . . . . .

Figure

Page

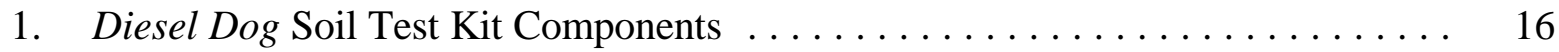

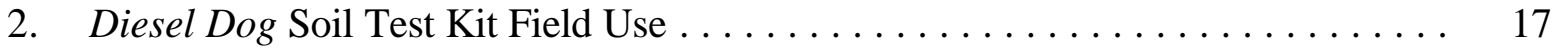




\section{EXECUTIVE SUMMARY}

Western Research Institute (WRI) is commercializing Diesel Dog ${ }^{\circledR}$ Portable Soil Test Kits for performing analysis of fuel-contaminated soils in the field. The technology consists of a method developed by WRI (U.S. Patents 5,561,065 and 5,976,883) and hardware developed by WRI that allows the method to be performed in the field (patent pending). The method is very simple and does not require the use of highly toxic reagents. The aromatic components in a soil extract are measured by absorption at $254 \mathrm{~nm}$ with a field-portable photometer. WRI added significant value to the technology by taking the method through the American Society for Testing and Materials (ASTM) approval and validation processes. The method is designated ASTM Method D-5831-96, Standard Test Method for Screening Fuels in Soils. This ASTM designation allows the method to be used for federal compliance activities. In FY 99, twenty-five preproduction kits were successfully constructed in cooperation with CF Electronics, Inc., of Laramie, Wyoming. The kit components work well and the kits are fully operational. In the calendar year 2000, kits were provided to the following entities who agreed to participate as FY 99 and FY 00 JSR (Jointly Sponsored Research) cosponsors and use the kits as opportunities arose for field site work: Wyoming Department of Environmental Quality (DEQ) (3 units), F.E. Warren Air Force Base, Gradient Corporation, The Johnson Company (2 units), IT Corporation (2 units), TRC Environmental Corporation, Stone Environmental, ENSR, Action Environmental, Laco Associates, Barenco, Brown and Caldwell, Dames and Moore Lebron LLP, Phillips Petroleum, GeoSyntek, and the State of New Mexico. By early 2001, ten kits had been returned to WRI following the six-month evaluation period. On return, the components of all ten kits were fully functional. The kits were upgraded with circuit modifications, new polyethylene foam inserts, and updated instruction manuals.

Some of the kits had been used for site evaluation and cleanup activities. ENSR, of Acton, Massachusetts, used a Diesel Dog Portable Soil Test Kit to evaluate sites in the Virgin Islands and Georgia. Barenco, Inc. is using a Diesel Dog Portable Soil Test Kit for site evaluation at a paper mill site in Canada. A small spill of about three gallons of diesel fuel was cleaned up in the Laramie, Wyoming, area in one morning using a Diesel Dog Soil Test Kit. The Wyoming DEQ successfully used a Diesel Dog Soil Test Kit for a cleanup project at a decades-old, fuel-contaminated site near Jackson, Wyoming. The site was contaminated with diesel fuel and road oil in a heavy, wet clay. Other sites were also excavated by the Wyoming DEQ.

A poster describing field use of the Diesel Dog Soil Test Kit was presented at the EPA/ACS Waste Testing and Quality Assurance Symposium in Washington, D.C. in August 2000. An invited presentation on method development activities leading to Diesel Dog Soil Test Kit development was made at the Dine' Navajo Nation College at Shiprock, New Mexico, in August 2000. A Diesel Dog Soil Test Kit was shown at contaminated soils and groundwater conferences in San Diego, California, in March 2000 and Amherst, Massachusetts, in October 2000. An abstract on Diesel Dog Soil Test Kit use was prepared with Eric Butler of Gradient Corp., Cambridge, Massachusetts, 
for the First International Congress on Petroleum Contaminated Soils, Sediments \& Water, which will be held in London in August 2001. 


\section{OBJECTIVES}

One objective of the current work was to complete the final assembly of twenty-five Diesel Dog ${ }^{\circledR}$ Soil Test Kits and provide them to the cosponsors for field site evaluation. The cosponsors were to perform field evaluations using the test kits as appropriate projects arose. Western Research Institute (WRI) also provided technical support, assisted in interpreting and communicated results, and modified the test kits based on feedback from the field experience.

\section{INTRODUCTION}

\section{Background}

A new method for measuring fuels in contaminated soils was developed by WRI in response to the recent banning of the use of ozone-depleting chlorofluorocarbons such as Freon ${ }^{\circledR}$. Up to that point, the standard EPA (Environmental Protection Agency) method required the extraction of soil with Freon followed by measurement of the amount of carbon-hydrogen bonds with infrared spectroscopy. The WRI Diesel Dog Soil Test Kit uses a new method that involves extracting soil with isopropyl alcohol followed by measuring the aromatic rings in the fuel by ultraviolet photometry. The patented WRI soil test kit technology consists of a method for screening soils for fuel contamination (U.S. Patents 5,561,065 issued October 1, 1996 and 5,976,883 issued November 2, 1999). The method was approved in 1995 as American Society for Testing and Materials (ASTM) D-5831, Standard Test Method for Screening Fuels in Soils. Hardware developed by WRI (patent pending) allows the method to be performed in the field. WRI and CF Electronics, Inc., of Laramie, Wyoming, set up production capabilities and constructed twenty-five fully operational Diesel Dog Test Kits in FY 99. As a cost share to the FY 99 and FY 00 efforts, twenty environmental companies and state agencies and F.E. Warren Air Force Base agreed to receive Diesel Dog Test Kits and evaluate them as opportunities arose beginning in early 2000 for a nominal six-month period. The last of the twenty kits was delivered to the State of New Mexico on August 24,2000 . The cosponsors are several environmental engineering firms and state agencies that have agreed to evaluate the preproduction prototype units that were designed and assembled as part of the current task. The particular application of interest is using the portable test kits to screen fuelcontaminated soils in the field for site evaluation and excavation activities.

The presence of diesel fuel and heavier fuels in soils is an important environmental issue. State cleanup standards are typically site specific, and are either health-based or arbitrary. A typical recommended cleanup standard is $100 \mathrm{mg} / \mathrm{kg}$, although these vary from state to state (Simmons et al. 2000). Health-based guidelines range from 1,166 to $11,287 \mathrm{mg} / \mathrm{kg}$ (Millner et al. 1992). As the diesel in soil is weathered and subjected to bacterial degradation, the remaining fuel is more aromatic and less volatile than the starting material (Douglas et al. 1992). Unlike more volatile gasoline, 
diesel fuel cannot be readily measured using a portable organic vapor analyzer (OVA) based on either photoionization or flame ionization detection.

U.S. EPA laboratory methods are based on Soxhlet or ultrasonic extraction of soils prior to the measurement of organics such as those occurring in diesel fuels using gas chromatographic (GC) separation (EPA 1986). The Massachusetts Department of Environmental Protection extractable petroleum hydrocarbon (MADEP EPH) method involves an additional step of removing solvent from a soil extract and redissolving the extract into heptane prior to separation into saturate-rich and aromatic-rich fractions using a silica-based, Sep Pak ${ }^{\mathrm{TM}}$, syringe-mounted cartridge (Schabron et al. 1997). These methods provide some information on the type and distribution of fuel components; however, they are not suitable for field use. A variety of field screening methods have been introduced to define the boundaries of contamination and to allow informed decisions to be made as to where samples should be taken for the more expensive and extensive laboratory analyses. Such methods also can result in cost savings for site excavations by minimizing the incidence and cost of unnecessary removal of uncontaminated soils. These methods are described in the following section.

All field and laboratory methods for analyzing soils for hydrocarbon contaminants are only as good as the knowledge about and the availability of a sample of the specific contaminant for standardization (Rhodes et al. 1996). Since the contaminant fuel is rarely available for calibration, the results are dependant on the method and calibration material used. Thus, the various methods rarely provide comparable or truly accurate results. The common laboratory methods, which involve gas chromatographic separations, usually disregard the presence of materials heavier than dieselrange contaminants. Thus, used motor oil and fuel oil contaminants are rarely reported. No two fuel analysis methods (lab or field) should be expected to give the same answer because of the tremendous variation in fuels and the different principles of measurement. Typically, a laboratory reference method is agreed upon by the regulatory agency, the site owner, and contractor. A field screening method is often used to select the points from which samples are collected for the laboratory analysis. The manner in which a field screening method relates to the laboratory standard method can become an issue in cleanup activities. It is important that the field method does not provide false negative results when guiding rapid cleanup and excavation activities. In environmental management activities, both field and lab method selection are very important to the overall remediation design.

\section{Current Field Methods}

Several approaches are available for field testing for various types of fuel contaminants in soils. Typically, TPH, for Total Petroleum Hydrocarbons, is used interchangeably and loosely. Each approach has strengths and weaknesses that must be understood so that it is used appropriately. As mentioned above, none of the response factors are necessarily "correct," unless the exact fuel that is being determined is used for calibration. Fuels purchased at different filling stations and at 
different times around the country will show variations in composition. This is particularly true of diesel fuels, which have a higher boiling range than gasoline and can contain a wider variety of components. The results of any test kit or laboratory method for fuels, including the one described in this report, will be dependent on the fuel source and type.

A kit for measuring TPH in soil using a chlorofluorocarbon solvent extraction followed by slow gravity filtration and infrared (IR) spectroscopy measurement has been described (Grant and Taliadourous 1992). This methodology requires a solvent that does not contain the C-H functionality, which is what is measured by IR. This is the reason that chlorofluorocarbon solvents such as Freon have been used in the past. The use of such solvents has been phased out because of the deleterious effect the solvent vapors can have on the earth's ozone layer and their persistence in the environment. Recently, IR methods have been modified to use tetrachloroethylene (a carcinogen) as a solvent.

A kit is available that performs a soil extraction with methanol using manual agitation. The extract is mixed with salt water, which renders the hydrocarbon insoluble and results in a cloudy, emulsion-like appearance (Dexsil 1995). Fuel content is estimated by measuring the resulting turbidity. Since solubility is the key to this measurement, any variable that affects solubility can affect the results. For example, water acts as a negative interference because it is difficult to extract hydrocarbon from a wet soil. Solubility is also affected by the aliphatic component of the fuel molecules and the temperature of the analysis.

An immunoassay field test kit for hydrocarbon contamination has been developed (Allen et al. 1992). Immunoassay uses a methanol extraction performed by manual extraction with methanol followed by several steps for visual color development. The development components must be refrigerated until they are used. Reaction rates for the multiple steps are temperature dependent, and skilled operators are required. For these reasons, the utility of immunoassay methods for field analysis has been questioned (Friedman 1996).

A kit based on the Friedel-Krafts alkylation reaction for detecting aromatic rings is also available (Hanby 1995). The catalyst in this kit reacts violently with water, and the solvent used for extraction contains carbon tetrachloride, a carcinogen. Wet clay soils are difficult to extract because of poor mixing with the extraction solvent, which is a mixture of heptane and carbon tetrachloride.

\section{WRI Diesel Dog Portable Soil Test Kit Technology}

A new field screening method was developed by WRI for determining the presence of fuels containing aromatic components, particularly diesel and heavier fuels in soils (Schabron et al. 1995). The patented technology consists of a method for screening soils for fuel contamination (U.S. Patents 5,561,065 and 5,976,883) and hardware developed by WRI that allows the method to be 
performed in the field (patent pending). WRI added significant value to the technology by taking the new soil screening method through the ASTM approval and validation processes. National acceptance has been facilitated by the existence of ASTM Standard D-5831, Standard Test Method for Screening Fuels in Soils. In addition, public law 104-113 (March 7, 1996) states, “...all federal agencies and departments shall use technical standards that are developed by voluntary consensus standards bodies."

The method measures the aromatic components in a soil extract by absorption at $254 \mathrm{~nm}$ with a laboratory spectrophotometer or a field-portable photometer. The method is very simple. It does not involve complicated color development steps or require the use of highly toxic reagents. The method involves mixing $5 \mathrm{~g}$ of soil with $5 \mathrm{~g}$ of calcium oxide, which dries the soil and binds humic materials to minimize interference. The soil is then extracted for three minutes with a 10:1 ratio (v:w) of reagent-grade isopropyl alcohol using mechanical mixing. Extraction is not performed by manual agitation, as is the common practice for most field analysis methods, because manual agitation has been shown to be inefficient and nonrepeatable (Schabron et al. 1995). Therefore, for field analysis, a mechanical $12-\mathrm{V}$ extractor having only glass, Teflon ${ }^{\circledR}$, and stainless steel wetted parts is provided with the Diesel Dog Soil Test Kit. The extract is filtered with a disposable, Teflon, syringe filter and its absorbance is read at $254 \mathrm{~nm}$ using a 12-V portable photometer. This provides a direct measurement of the aromatic components, which are the most persistent in the environment over time and represent the most toxic of fuel components. The components of the test kit are shown in Figure 1. New or old fuel-contaminated sites with diesel or heavier (fuel oil, petroleum, coal tar) fuels are best evaluated with this method. Lighter fuels, such as gasoline, are best screened with OVAs (organic vapor analyzers). OVAs are not suitable for measuring diesel or heavier fuels. To screen for both light and heavy contaminants, both an OVA and a Diesel Dog Soil Test Kit should be used in the field. The various aspects of the ASTM method and its performance with various soil and fuel types have been discussed in detail elsewhere (Schabron et al. 1995; Schabron et al. 1998).

The ASTM method can be used for three tiers of analysis. If a sample of the contaminant fuel is available for calibration of the photometer, a quantitative analysis can be performed. If the contaminant fuel type is known but a sample of the contaminant fuel is not available for calibration, an estimate of the concentration can be determined using average response factors provided in the method. If the nature of the contaminant is unknown, the screening method can be used to identify the possible presence of contamination. 


\section{RESULTS AND DISCUSSION}

\section{$\underline{\text { Case Studies }}$}

WRI participated with CF Electronics, Inc., of Laramie, Wyoming, in the design and assembly of twenty-five preproduction units and the set up of commercial production capabilities. A typical use of the soil test kit in the field is on the tailgate of a pickup truck (Figure 2). Prototype test kits were used in a national study to validate the new ASTM method (Sorini and Schabron 1997). The method has been tested successfully with a variety of soils, fuel types, and conditions (Butler et al. 1997; Schabron et al. 1997; Sorini et al. 1997; Sorini and Schabron 1996). Several environmental engineering firms and state agencies agreed to use the preproduction test kits at field sites as the opportunity arose. Kit performance was evaluated, and this input was used to make modifications to the kits as required. In addition, data and information from the use of the kits at field sites provided examples of the various uses of the Diesel Dog Soil Test Kits and information on the performance of the kits. The use of the Diesel Dog Soil Test Kits at field sites is summarized in the following sections.

\section{Aged-Diesel Pond Site}

ENSR Corp., of Acton, Massachusetts, used a Diesel Dog Soil Test Kit at a field site in the U.S. Virgin Islands at a Domino Oil/Enighed one-year-old pond site impacted by diesel fuel. The soil tested in the area was very wet and sandy. Diesel Dog (ASTM D-5831) field analyses were compared with more expensive and lengthy MADEP EPH laboratory analyses. The results are provided in Table 1. Both the field method and the lab method detected hydrocarbon in all of the samples. Diesel Dog Soil Test Kit results were higher than the lab results for five of the eight samples that were analyzed by both methods.

\section{Diesel-Contaminated Site}

ENSR Corp. also used a Diesel Dog Soil Test Kit at a site in Georgia contaminated with diesel fuel. The kit was used to screen drilling points. Data comparing the Diesel Dog (ASTM D5831) method with the laboratory EPA $8015 \mathrm{~B}$ GC method are provided in Table 2 . The estimated quantitation limit (LOQ) for ASTM D-5831 for diesel fuel is $75 \mathrm{mg} / \mathrm{kg}$. Of the 17 samples analyzed by both methods, 10 were near or below a typical action level of $100 \mathrm{mg} / \mathrm{kg}$ by both methods. These would be considered clean. Four samples that showed $<12 \mathrm{mg} / \mathrm{kg}$ by the EPA 8015B laboratory method showed contamination levels of 120, 130, 930, and $1700 \mathrm{mg} / \mathrm{kg}$ by ASTM D-5831. The laboratory method missed contamination in these four samples. Three samples showed significant contamination by both methods, and for two of these the Diesel Dog results were higher. In none of the samples did the Diesel Dog kit fail to detect contaminant. The results from this study show that if a Diesel Dog Soil Test Kit was used to guide an excavation at this site, the user could be 
confident that laboratory data generated by the EPA Method 8015B would show that the cleanup had been performed completely and successfully.

\section{Decades-Old Diesel and Road Tar Site}

The Wyoming DEQ used a Diesel Dog Soil Test Kit to guide excavation at a decades-old, fuel-contaminated, site cleanup near Jackson, Wyoming. The site was contaminated with diesel fuel and road oil from prior transportation department activities. The soil was a heavy, wet clay. Under supervision of the Wyoming DEQ, the engineering firm Dames and Moore excavated about 6,000 cubic yards of soil, including about 2,000 cubic yards of overburden. OVAs based on photoionization were not able to detect the contamination because the fuel had weathered severely. A Diesel Dog Portable Soil Test Kit was used by a chemical engineer and a civil engineer on the tailgate of a pickup truck to provide rapid field analysis. The Diesel Dog Soil Test Kit provided data within minutes. The results were typically higher than the laboratory GC results. This was most likely due to the ability of isopropyl alcohol to extract and detect the more aromatic components of weathered fuel, which are the most persistent in the environment. Data comparing Diesel Dog Soil Test Kit results with laboratory GC results are provided in Table 3. The laboratory data were obtained by a purge-and-trap sampling method for total volatile petroleum hydrocarbons (TVPH, $\mathrm{C}_{6}-\mathrm{C}_{10}$ ) and by solvent extraction for total extractable petroleum hydrocarbons ( TEPH, $\mathrm{C}_{11}-\mathrm{C}_{28}$ ). The results for the test kit are significantly higher than the laboratory results if the absorbance signal is interpreted in terms of the average response factor for diesel fuel (209 mg/L/AU) (ASTM 1999). However, the site was contaminated with both diesel fuel and road tar. The location of the site in Wyoming suggests that the road tar was from the highly aromatic, Recluse, Wyoming, sour oil. If the absorbance is interpreted in terms of a coal oil response factor that corresponds to a highly aromatic oil (58.7 mg/L/AU), the numerical results are about four times lower (Table 3). These results show no significant contamination in samples 1-6. However, significant contamination requiring action is shown in samples 8 and 9. This contamination was detected by the Diesel Dog Soil Test Kit as a "hot spot" area within two days before the termination of site activities. The highly contaminated area was successfully excavated using Diesel Dog Soil Test Kit results alone, and confirmation was obtained from laboratory analysis more than a week after the site cleanup effort was terminated. The Diesel Dog equipment operated reliably, and the field personnel indicated that the Diesel Dog Soil Test Kit successfully guided their site cleanup efforts.

\section{Filling Station Site}

The Wyoming DEQ conducted an excavation project involving the removal and disposal of 9,200 cubic yards of contaminated soils at a filling station site. Contamination was from two recent gasoline spills and several smaller, older spills. The area of the plume was known from earlier site investigations. Depth to groundwater varied from seven to nine feet below the surface. Four soil samples were taken from within the excavation, two from the bottom and two from the side walls. 
It was assumed that the side wall samples were not contaminated. The results from the Diesel Dog Soil Test Kit analyses for the side wall samples showed no contamination. The samples from the bottom of the excavation contained 180 and $220 \mathrm{mg} / \mathrm{kg}$ according to the Diesel Dog Soil Test Kit results. The corresponding laboratory GC analysis results were 32.5 and $66.7 \mathrm{mg} / \mathrm{kg}$, respectively for gasoline to diesel-range fuels. The Diesel Dog Soil Test Kit results were higher than the laboratory GC results, which is typical for weathered fuel contamination, as discussed in the prior section.

\section{Bus Barn Site}

The Wyoming DEQ conducted an excavation of 2,670 cubic yards of contaminated soil from a transportation depot facility. The ground was contaminated because of leakage from an underground storage tank that had been removed in 1989. Following the excavation, two soil samples were collected from a side wall and analyzed with a Diesel Dog Soil Test Kit. No contamination was detected from the analyses, and it was not deemed necessary to follow-up with laboratory analysis.

\section{Emergency Response for Diesel Spill}

A contractor was hired at a private residence in Laramie, Wyoming, to steam-clean the carpets and upholstery. The steam-cleaning equipment was in a large trailer that contained a diesel engine to power the equipment and heat a large tank of water. The contractor was on-site for several hours. When the contractor had finished and left the premises, the smell of diesel fuel was quite apparent in the soil in the area where the trailer had been parked. Closer inspection revealed a diesel spill that had flowed to the edge of the driveway into the soil and gravel. The exact perimeter of the spill was difficult to ascertain because a lawn sprinkler had soaked the general location after the contractor had left. The homeowner was concerned because the spill was only about 15 feet away from the home's private water well. The contractor was called, and he estimated the spill to be about 5 to 10 gallons. Although there was little chance that this amount of diesel could penetrate the soil to the aquifer 150 feet below, there was the potential that the well and aquifer could become contaminated via the well casing. If the outside of the casing and the surrounding bedrock had not been sealed with concrete at the time the well was drilled, surface water could flow down the outside of the well casing into the aquifer below.

A Diesel Dog Portable Soil Test Kit was used at the residence to determine the level of diesel contamination and provide a reliable means to determine the extent of excavation needed to remediate the spill to proper cleanup standards. The Wyoming DEQ regulatory level of $100 \mathrm{mg} / \mathrm{kg}$ was used as the remediation standard. Since the soil and gravel were visibly stained dark in the most concentrated region of the spill, this area was first excavated with a shovel. The soil and gravel in this area smelled quite strongly of diesel, which suggested that its removal was necessary. 
Eventually, a semicircle at the edge of the driveway about 5 feet wide and 2 feet deep was excavated before the boundary of the spill became certain. With a reliable quantitative field method, it was fast and simple to determine when and where the excavation should cease.

The test kit was used on the tailgate of a Jeep ${ }^{\circledR}$. Three soil samples equally spaced around the inside perimeter of the $5 \mathrm{ft} \times 2 \mathrm{ft}$ semicircular hole were analyzed. The results are provided in Table 4. Data from samples 1 and 2 showed that the first excavation was sufficient to collect all of the spill that had absorbed lengthwise and depthwise into the soil. Data from the third sample showed extensive diesel contamination under the concrete driveway where the diesel had drained. As a result, additional excavation was necessary. Two more analyses were conducted after the second excavation (samples 4 and 5). These showed the site to be in compliance with the Wyoming DEQ cleanup level of $100 \mathrm{mg} / \mathrm{kg}$. Once it was established that the level of diesel in the soil was $<100 \mathrm{mg} / \mathrm{kg}$, the cavity was backfilled with clean fill.

Both the homeowner and contractor were confident that the spill had been cleaned to proper levels, and that the possibility of aquifer and well contamination and litigation had been avoided. Each analysis took only a few minutes, and was conducted just a few steps from the excavated spill location. The contractor, who had no laboratory or field analysis experience, volunteered to perform the analyses for samples \#4 and \#5. He found the procedure easy to learn and was impressed with the meaningful results.

\section{Underground Storage Tank Site}

Dames and Moore Lebron LLP used a Diesel Dog Soil Test Kit at an underground storage tank (UST) site. The users stated that it worked very well and that there was good correlation between the soil test kit data and laboratory data. Data will be provided in the future.

\section{Communication of Results}

A poster describing field use of the Diesel Dog Soil Test Kit was presented at the EPA/ACS Waste Testing and Quality Assurance Symposium in Washington, D.C. in August 2000. An invited presentation on method development activities leading to Diesel Dog Soil Test Kit development was made at the Dine' Navajo Nation College at Shiprock, New Mexico, in August 2000. A Diesel Dog Soil Test Kit was shown at contaminated soils and groundwater conferences in San Diego, California, in March 2000 and Amherst, Massachusetts, in October 2000.

\section{CONCLUSIONS}

Field evaluation work was initiated with Diesel Dog Portable Soil Test Kits. Data were generated that were compared with data from more costly and time-consuming laboratory methods. 
In general, the Diesel Dog Soil Test Kits (ASTM D-5831) provided higher values than the MADEP EPH method and the EPA 8015B method with no false negative results. The Diesel Dog Soil Test Kit field analysis provides a rapid, inexpensive screening tool for site evaluation and cleanup activities. 


\section{REFERENCES}

Allen, R.L., W.B. Manning, K.D. McKenzie, T.A. Withers, J.P. Mapes, and S.B. Friedman, 1992, A Rapid and Sensitive Immunoassay for the Detection of Gasoline and Diesel Fuel in Contaminated Soil. Journal of Soil Contamination, 1(3): 227-237.

American Society for Testing and Materials, 1999, D-5831-96, Standard Test Method for Screening Fuels in Soils. Annual Book of ASTM Standards, Vol. 11.04, 327-334.

Butler, E.L., S.H. Frisbie, J.F. Schabron, S.S. Sorini, and A.D. Wait, 1997, New ASTM TPH Screening Method. Environmental Laboratory, February-March, 11-14.

Dexsil, 1995, Petro Flag ${ }^{\mathrm{TM}}$ Product Literature and Instruction Manual, Dexsil Corporation, Hamden, CT.

Douglas, G.S., K.J. McCarthy, D.T. Dahlen, J.A. Seavey, W.G. Steinhauer, R.C. Prince, and D.L. Elmdorf, 1992, The Use of Hydrocarbon Analyses for Environmental Assessment and Remediation, in Kostecki, P.T., and E.J. Calabrese, eds., Contaminated Soils - Diesel Fuel Contamination. Lewis Publishers, Chelsea, MI, 1-21.

EPA, 1986, Test Methods for Evaluating Solid Waste, SW-846, Third Edition, U.S. Environmental Protection Agency, Washington, D.C.

Friedman, S.B., 1996, Immunoassay - Separating Fact from Fiction. Environmental Lab, December-January, 28-31.

Grant, M., and K. Taliadourous, 1992, TPH Field Screening Methodology Using Portable Infrared Instrumentation: A Case Study. Presented at the Seventh Annual Conference on Hydrocarbon Contaminated Soils, September 22, U. of Massachusetts, Reprint from the Foxboro Co., Foxboro, MA.

Hanby Environmental Laboratory Procedures Inc., 1995, Field Test Kit for Fuels Product Literature, Wimberly, TX.

Millner, G.C., R.C. James, and A.C. Nye, 1992, Human Health-Based Soil Cleanup Guidelines for Diesel Fuel No. 2. Journal of Soil Contamination, 1(2): 103-157.

Rhodes, I.A.L., E.M. Hinojosa, D.A. Barker, and R.A. Poole, 1996, Conventional TPH Pitfalls. Environmental Lab, December/January 1995/96, 16-20. 


\section{REFERENCES (continued)}

Schabron, J.F., N.D. Niss, B.K. Hart, and S.S. Sorini, 1995, Remote Chemical Sensor Development: A New Field Screening Method for Soil Fuel Contamination. Laramie, WY, WRI Report to DOE, WRI-95-R016.

Schabron, J.F., S.S. Sorini, E.L Butler, and S. Frisbie, 1997, Field Evaluation of a Standard Test Method for Screening Fuels in Soils at a Railroad Site. Proceedings of the 1997 USEPA/A\&WMA International Symposium on Field Screening Methods for Hazardous Wastes and Toxic Chemicals, Air \& Waste Management Association, 238-243.

Schabron, J.F., N.D. Niss, B.K. Hart, and S.S. Sorini, 1998, Determination of Diesel Fuel in Soil by Extraction and Ultraviolet Photometry. AT-Onsite, III, 1-4, 32-48.

Simmons, K., P. Kostecki, and E. Calabrese, 2000, State-by-State Summary of Cleanup Standards. Soils, December 1999-January 2000: 24-51.

Sorini, S.S., and J.F. Schabron, 1996, Evaluation of a Standard Test Method for Screening Fuels in Soils. Proceedings of the 1996 EPA/ACS Waste Testing and Quality Assurance Symposium, Washington, D.C., 51.

Sorini, S.S., J.F. Schabron, J.R. Bowes, and S.H. Frisbie, 1997, ASTM TPH Screening Method Works for Heavier Fuel Products. Soil and Groundwater Cleanup, October, 14.

Sorini, S.S., and J.F. Schabron, 1997, Development and Precision Testing of a Standard Test Method for Screening Fuels in Soils. Journal of Testing and Evaluation, JTEVA, 25 (4): 400 . 
Table 1. Diesel Dog Test Kit (ASTM D-5831) Field Data and MADEP EPH Lab Data for Domino Oil/Enighed Pond Site, mg/kg

\begin{tabular}{|c|c|c|c|c|}
\hline \multirow[b]{2}{*}{$\underline{\text { Sample }}$} & \multirow{2}{*}{$\begin{array}{l}\text { ASTM D-5831 } \\
\text { Diesel Dog }\end{array}$} & \multicolumn{2}{|c|}{ MADEP EPH } & \multirow[b]{2}{*}{ Total } \\
\hline & & Aliphatics (C9-C36) & Aromatics (C11-C22) & \\
\hline $1 \mathrm{AA}$ & 2200 & 110 & 10 & 120 \\
\hline $2 \mathrm{AA}$ & 3500 & 12600 est. & $<9$ & 12600 est. \\
\hline 3AA & - & 390 & 98 & 488 \\
\hline 4AA & 6900 & 6300 & 1600 & 7900 \\
\hline $4 \mathrm{AB}$ & 3700 & 2150 & 460 & 2610 \\
\hline $6 \mathrm{AA}$ & 7600 & 14000 & 3200 & 17200 \\
\hline 7AA & 2100 & 388 est. & 92 est. & 480 est. \\
\hline 7AA Replicate & - & 284 & 41 est. & 325 est. \\
\hline 8AA & 1400 & - & - & - \\
\hline 9AA & 5000 & 299 & 71 & 370 \\
\hline $10 \mathrm{AA}$ & 1200 & 43 & 13 & 56 \\
\hline
\end{tabular}


Table 2. Diesel Dog Test Kit (ASTM D-5831) Field Data and EPA SW846 8015B Lab Data for Proprietary Diesel Spill Site in Georgia, mg/kg

\begin{tabular}{lll}
\hline Sample & $\begin{array}{c}\text { ASTM D-5831 } \\
\text { Diesel Dog }\end{array}$ & $\begin{array}{c}\text { EPA SW846 } \\
8015 \mathrm{~B}\end{array}$ \\
101 & 130 & $<12$ \\
102 & 92 & $<12$ \\
103 & 83 & $<12$ \\
104 & 1100 & 410 \\
105 & 930 & 8.7 est. \\
106 & 19 & $<12$ \\
107 & 380 & 570 \\
108 & 43 & $<12$ \\
109 & 86 & 13 \\
110 & 78 & $<12$ \\
111 & 40 & 5.3 est., 34 \\
112 & 55 & $<12$ \\
113 & 1700 & 3 est. \\
114 & 72 & 3.7 est. \\
115 & 77 & 4.1 est. \\
117 & $>2000$ & - \\
118 & 5300 & 1300 \\
119 & 120 & $<12$ \\
& & \\
\hline
\end{tabular}

${ }^{\text {a }}$ Approximate quantitation limit is $75 \mathrm{mg} / \mathrm{kg}$ for diesel fuel 
Table 3. Diesel Dog Test Kit (ASTM D-5831) Field Data and EPA SW846 8015B Lab Data for Decades-Old Diesel and Road Tar Site in Jackson, WY, mg/kg

\begin{tabular}{|c|c|c|c|c|c|}
\hline \multirow{2}{*}{$\underline{\text { Sample }}$} & \multicolumn{2}{|c|}{$\begin{array}{c}\text { ASTM D-5831 } \\
\text { Diesel Dog }{ }^{\text {a }} \text { Test Kit }\end{array}$} & \multicolumn{3}{|c|}{$\begin{array}{c}\text { EPA SW846 } \\
8015 B \\
\end{array}$} \\
\hline & As Diesel & As Coal Tar & TVPH & TEPH & Total \\
\hline 1 & 490 & 130 & 1.1 & $<9$ & 1.1 \\
\hline 2 & 150 & 40 & 1.3 & $<9$ & 1.3 \\
\hline 3 & 610 & 160 & 12 & $<9$ & 12 \\
\hline 4 & 300 & 81 & 5.2 & 9 & 14 \\
\hline 5 & 150 & 40 & $<0.5$ & $<9$ & $<10$ \\
\hline 6 & 300 & 81 & $<0.5$ & $<9$ & $<10$ \\
\hline 7 & 6000 & 1600 & 800 & 870 & 1670 \\
\hline 8 & 7200 & 1900 & 880 & 3100 & 3980 \\
\hline
\end{tabular}

${ }^{\text {a }}$ Approximate quantitation limit is $75 \mathrm{mg} / \mathrm{kg}$ as diesel fuel, $20 \mathrm{mg} / \mathrm{kg}$ as coal tar 
Table 4. Diesel Dog Test Kit Analysis Results at Diesel Spill Emergency Response Site

$\underline{\text { Sample ID }}$

First Excavation

1. 8" deep

2. 4" deep

3. 1" behind concrete edge

Second Excavation

4. 8" behind concrete edge

5. 8" behind concrete edge $\underline{\mathrm{mg} / \mathrm{kg} \text { as Diesel }}$

\author{
51 \\ 98 \\ 20,000
}

73

69 




Figure 1. Diesel Dog Soil Test Kit Components 




Figure 2. Diesel Dog Soil Test Kit Field Use 